\title{
SWOT Analysis on the Development of "The Silk Road" Sports Tourism in Yunnan Province
}

\author{
Peipei Yang ${ }^{1}$ \\ ${ }^{1}$ Oxbridge College, Kunming University of Science and Technology, China
}

Keywords: Yunnan, sports tourism of "The Silk Road", SWOT analysis.

\begin{abstract}
Yunnan plays an important role in the Southern Silk Road because of its geographical position, which is a bridge connecting Chengdu with South Asia and Southeast Asia. By adopting SWOT analysis, this paper analyzed the advantages and disadvantages, opportunities and threats of Yunnan Silk Road sports tourism and find out the restricting factors of the development of Yunnan Silk Road sports tourism and put forward the prominent regional characteristics and ethnic characteristics. The development should be market-oriented and the development of sports tourism resources should be planned step by step. In addition, some brand competition activities are excepted in order to implement the strategy of hitch-hiking.
\end{abstract}

\section{Introduction}

The Silk Road is consisted of three parts: the North Silk Road, the South Silk Road and the Maritime Silk Road. Yunnan is located in the South Silk Road. In history, the Silk Road was called "Shu - Hindu Road". The road starts from Chengdu, Sichuan and then divides into two roads of west and east. The West Road goes along with the "yak road", passes through Ya'an, Hanyuan, Yuexi, Xichang, Huili, Panzhihua, Dayao and gets to Dali; the East Road passes Leshan, Qianwei, Yibin, Yanjin, Daguan, Zhaodao, Hezhang, Xuanwei, Qujing, Kunming, Chuxiong and gets to Dali. After the converge, the two roads pass Baoshan, Tengchong, and finally get to to Burma and India from Ruili. [1] From above routes it can be seen, Yunnan is connected to the North Silk Road in the north, and the Maritime Silk Road in the south. In China, Yunnan is the only province which is linked with Southeast Asia and South Asia by land routes. The unique geographical advantages contribute to Yunnan's irreplaceable place in the strategic framework of the Silk Road.

SWOT analysis is a practical method to analyze influence factors of regional tourism when making regional tourism plans and development strategies.[2] It analyzes the strengths, weaknesses, opportunities and threats of the regional tourism industry. The strength and weakness of regional tourism refer to internal environment; opportunity and threat refer to the external environment when developing tourism in this region, or external factors. Based on comprehensive analysis of internal and external environment of that region, tourism products and resources with competitive advantages can be developed.

Strength Analysis. Analysis on natural resources of sports tourism. Tourism resources are also sports tourism resources. As an important hub of the Silk Road, Yunnan is an important demonstration area in "The Belt and Road" strategy. In the activity of "Silk Road Tourism Year" held in Yunnan, Yunnan Tourism Commission vigorously promoted the development of tourism from tourism products and regional cooperation, and achieved good effects in tourism industry and market. Yunnan develops two leisure tourism routes related to the "Silk Road": Dal trip and trip to the hometown of Nie Er, a famous musician; two ecotourism tour lines: tour to Baoshan, viewing sea of flowers and tour to Lincang, appreciating tea culture; two sightseeing lines: free trip to the border of Wenshan, and South Silk Road trip in Zhaoshui; two travel photography lines: bird photography trip in Baoshan, Baihualing and Red River Alley trip in Ailaoshan; two health-keeping tourist routes: Pu'er health tour and Wenshan pseudo-ginseng health tour.

Human resources advantages in sports tourism. Sports Tourism in Yunnan Silk Road is rich in cultural relics and culture of ethnic minorities. According to its own advantages, Yunnan has developed cultural, folk and The Ancient Tea Horse Road tourism routes. Two cultural tourist lines 
are Baoshan South Silk Road trip and Xishuangbanna tropical rain forest scenic tour; two folk tourism lines are ecological tour in the green triangle of Pu'er, and Wa Nationality Folk Tour in Cangyuan; two Ancient Tea Horse Road tourist routes are tea cultural tours in the border of Xishuangbanna and the tea horse road trip in Lincang.

Location and transportation advantages. Yunnan is located in the ancient South Silk Road, bordering three countries of Vietnam, Laos and Burma. It is connected to the Pacific Ocean and the India Ocean by land routes, and connected to three markets of Southeast Asia, South Asia and West Asia. In the beginning of the implementation of Western Development Strategy, Yunnan Provincial Party Committee considered the situation, and made a strategic decision to build an international thoroughfare to connect Southeast Asia and South Asia. For highway construction, the aim is to improve the level of road network, accelerating the construction of "seven entrances" and "four exits"; for railway construction, four new lines of Yunnan-Tibet, Kunming-Shanghai, Chongqing-Kunming and Yunnan-Guangxi are constructed; railways connecting Yunnan with Vietnam, Thailand and Burma are gradually constructed; for civil aviation, twelve civil airports have been opened, Changshui International Airport has become the airport hub in the southwest of China which linking Southeast Asia and South Asia; for waterway construction, Yunnan is now building "two entrances and three exits" waterway network, vigorously developing international shipping in Lancang River-Mekong River, constructing Yangtze River as the golden waterway, vigorously developing Youjiang-Pearl River waterway, as well as tourism shipping in lake areas.

Weakness analysis. At present, the development of sports tourism resources in Yunnan "Silk Road" is still in primary stage of development; it does not reach the medium development period of "market oriented" or the advanced development stage of "leading market". Specific performances can be found in the following aspects. The urbanization and socialization degrees of most areas are in low levels; languages, ethnic customs and religious customs create cultural barriers; people there hold backward ideas and are lack of awareness on sports tourism resources, which hinder the transformation of tourism resources into market advantages and the sports industry advantages. Sports resources are poorly allocated. Sports venue construction seriously lags behind; there's no high level athletic competition; regional sports market is difficult to develop; the incentive power of sports industry is insufficient. These all lead to the low market degree. Thus, Yunnan has not developed influenced brand products. The infrastructure construction lags behind. Poor accessibility restricts the development of sports tourism. Compound sports tourism talents are not enough. There's no human resources complementary mechanism between sports industry and tourism industry; the authority is lack of innovation and integration consciousness. Modern civilization and traditional concepts coexist; economic development is relatively slow; people do not have awareness of environmental protection and investment. Financing channels are not smooth enough to form scale merit. All of those have become negative factors restricting the development of sports tourism resources in Yunnan Silk Road.

Opportunity analysis. Great tourism market demand and the implementation of the western development strategy.

With the development and progress of the society, as well as the improvement of people's living standard and the increase of leisure time, people's life style and consumption concepts have changed greatly. In recent years, with the rapid development of China's tourism industry, tourism market is in great demand. People's tourism demands are changing from traditional static, view seeing tourism to new dynamic, leisure sports tourism of participation and entertainment. The implementation of Western Development Strategy make western region become the focus at home and abroad. The state considers the "vigorously development of the third industry, include tourism industry" as one of the top five priorities in the western development. All these create favorable conditions for the development of sports tourism resource in Yunnan Silk Road .

Domestic and international special events and theme festivals. In recent years, relying on the geographical and cultural advantages of the ancient "Silk Road", Yunnan has successfully hosted a number of international sports events, including Kunming Marathon, Dali Marathon, Dongchuan Chinese Auto Motocross, Swimming Competition in Asian Open Water of Chinese Lancang River 
(Mekong River), and International Open Tournament of Kayak in Nu River. With the constant promotion of competition brands and scales, tourism products with domestic and international influences are formed. In addition, Dai Water-Sprinkling Festival, Yi Torch Festival, Mojiang Twins Festival, Yongde Mango Festival, Luoping Rape Flower Festival and other festivals are becoming more and more influential. These activities expand the influences of "Silk Road" at home and abroad, and provide excellent opportunities for the development of sports tourism resources and sports tourism industry.

Threat analysis. Sports tourism development in Yunnan Silk Road is faced with following threatens. From the current point of view, although tourism is the pillar industry of Yunnan Province, the focus is sightseeing tours of natural resources and ethnic customs. Sports tourism becomes accessory. The structures of tourism products are quite similar; market positioning of tourists sources are basically the same. These results in increasing risks of tourism investment and increasing costs of development, and further aggravate regional tourism competition, pose threats and severe challenges to sports tourism of Yunnan "Silk Road". Vandalism and other factors caused by fragile regional ecological environment and the poor public awareness on environmental protection. The investment ability is limited; financing channels are not smooth, Yunnan is unable to carry out resource survey and make scientific plans, which will lead to low level development, or even blind exploitation and repeated construction. As the starting point of the South Silk Road, Chengdu is also allying itself with cities along the southern Silk Road to innovate the cross-regional tourism cooperation mode, highlight "Silk Road Cross-regional Tourism Cooperation Organization", and jointly forge the southern Silk Road heritage international tourism brand.

\section{The Development Strategies of Yunnan Silk Road Sports Tourism Resources}

To emphasize the regional characteristics and national characteristics. Although there is no vast grassland, desert nor Gobi along Yunnan "Silk Road", it has the tropical rain forest, the ancient road whose characteristic is the tea and the rich ethnic cultural resources. In the development and construction of the sports tourism resources, to fully demonstrate the original, mysterious, vast and powerful natural landscape and the rough, simple, beautiful, rich ethnic customs and rich cultural heritage along Silk Road, we should combine the various festivals and activities of the ethnic minorities, comprehensively develop the sports tourism resources relying on a variety of resources with outstanding advantages, make efforts to strengthen the brand awareness, highlight the regional characteristics and national characteristics. Adhere to the principle of "I have something nobody has, I have better thing nobody has, I have best thing nobody has", we cannot blindly follow others, plan and develop with a higher starting, a higher concept and a higher level and make excellent sports tourism products.

To be market-oriented and to carry on the sports tourism resources development step by step. The development of tourism resources is the economic and technical system of tourism resources, the essence of which is to turn the tourism resources into the real tourist attractions. At present, the development of Yunnan Silk Road tourism resources is in the primary development stage with a low level, which has not yet been in the intermediate stage of the market-oriented development and the advanced stage of leading the market. Therefore, we should follow the principles of the market economy and take into account the needs of domestic tourists and the tastes of foreign tourists. In the early stages of the development, we should be quality-oriented, promote the development step by step, follow the principle of the sustainable development and reduce unreasonable duplication and waste of resources. The reasonable allocation and the highlighted focus will form the core area of regional sports tourism and promote the overall development of Yunnan Silk Road sports tourism.

To strengthen the macro management, overall planning, rational distribution and resource sharing. Under the unified coordination of the Yunnan provincial government, we should straighten out the relationship among the various departments in the development of the tourism resources, eliminate the obstacles on the system, unify the thoughts and unify the understanding. According to the distribution, characteristics and advantages of tourism resources along Yunnan Silk Road, the overall research and planning are carried out. Tourism Bureau, Sports Bureau and the relevant 
departments have worked together to strengthen the city's regularity, stable contact and cooperation among the cities (states), the overall planning, the scientific management and the local development according to its conditions. Adhere to the principle of "to be or not to be", we should establish an orderly and supporting the market competition mechanism to avoid the disorderly competition and ensure the fairness and equality during the development of sports tourism resources, which can make the sports tourism resources rational. We should mine and integrate the existing sports tourism resources, carry out the complementary characteristics and resource sharing, make efforts to build a regional sports tourism resources base, establish a diversified sports tourism resources network and share the resources.

To create brand events and implement the strategy of "lifting". In the development of sports tourism resources, we cannot blindly follow the others. We should take the regional advantage, create the sports tourism with local characteristics along the Silk Road, gradually form a monopoly, expand its influence, improve the popularity and the overall strength of the famous sports tourism resources along Yunnan Silk Road. We should also build a sports brand from the following three aspect. First, get a lift of tourist; second, get a lift of culture; third, get a lift of national characteristics. That is, the lifting strategy. Relying on the Kunming marathon, Dali marathon and some other international events, we can expand the domestic and international influence, improve visibility, highlight the internationality, long-term effectiveness and popularity, so that we can develop the sports tourism along the Silk Road.

To increase financing channels and to form a new pattern of diversified investment entities. In the development of resources, we should change the single mode of government investment and actively guide the social investment intentions and strength. The government should give certain support in taxes and encourage people to invest in sports tourism. With the principle of "who invests, who benefits", we should fully mobilize the enthusiasm of the social and personal investment, encourage the non-state-owned sports economy components with various forms promote the development of sports tourism resources, such as the sports enterprises, the consortia, the joint ventures and the private enterprises. At the same time, we should actively introduce the foreign investment, expand both domestic and foreign investment, so that we can gradually form a new pattern of the diversified development of sports tourism resources with the non-state-owned sports enterprises as the main subjects but dominated by the state-owned sports enterprises.

\section{References}

[1] Yu-xiang Jiang (editor). Study on the Ancient Silk Road in Southwest China (2nd edition) [M]. Sichuan University Press, 1995.

[2] Hong Tian. Applications of SWOT Analysis Method in the Development of Tourism in Gansu Province [J]. JOURNAL OF GANSU INSTITUTE OF PUBLIC ADMINISTRATION, 2003 (1).

[3] Yi-qun Li, Ling-di Ding \& Jian-guo Zhan, et al. Influences of Successfully Hosting the Olympic Games on Chinese Social Environment [J]. Chinese Sports Science and Technology, 2001 (7). 